\title{
SOCIAL INCLUSION OF ETHNIC MINORITIES THROUGH NON - FORMAL EDUCATION
}

\author{
V. Mareva* \\ Department of Social Activities, Faculty of Medicine, Trakia University, Stara Zagora, Bulgaria
}

\begin{abstract}
This article is provoked by the widening scope of non-formal education and its impact on the social inclusion of vulnerable groups, with a focus on ethnic minorities. Empirical data are derived from a study of the impact of informal learning activities on the social inclusion process of roma young people between the ages of 15 and 29 .
\end{abstract}

Key words: vulnerable groups, roma community, social inclusion, youth

\section{INTRODUCTION}

European societies face serious challenges related to poverty, accessible to education and the social inclusion of young people up to 29 years of age. This is precisely why social inclusion is one of the Council of Europe's main objectives in the youth policies. From the CoE perspective, social inclusion is a process of self-realization of the individual within a society, acceptance and recognition of personal potential by social institutions, integration (through research, employment, voluntary work or other forms of participation) in the social relations network in a community. In modern European societies, the concept is important for all young people who are in transition from family reliance to autonomy within a larger society under rapidly changing circumstances. Social inclusion in the context of youth has a special meaning for those young people who come from disadvantaged families and live in precarious conditions. (1)

Promoting social inclusion faces different challenges. The system of formal education aims to provide young people with basic knowledge to be used for their social inclusion in society. In many cases the formal education system fails to satisfy the needs of all young people for various reasons. Therefore other sources of personal development, such as nonformal education, are available. (2)

\footnotetext{
*Correspondence to: Vesela Mareva, PhD student, Department of Social Activities, Medical Faculty, Trakia University, Stara Zagora, Bulgaria, Sv. Kniaz Boris str. 138, app. 48, mobile phone number: +359886864143, e-mail: vesela.mareva@gmail.com
}

The definition of non-formal education characterizes it as an alternative or supplement to the traditional education system. Clarifying the boundaries between formal, non-formal and informal learning is extremely difficult. Non-formal education is defined as a set of procedures, tools and institutions specifically and specifically tailored to needs and training and education, but which are not directly aimed at giving a degree.

By nature, informal approaches allow us to reach a particular target audience in a different way, compensating for the inability of formal education to meet all the learning needs of the individual. Both formal and informal education itself is thematically differentiated, combining the following objectives:

- Supporting the overcoming of temporary educational difficulties or exclusion;

- Preventing lagging and dropping out of school;

- Preventive education programs;

- Special educational support for pupils with special needs and people with disabilities;

- The care of compensatory literacy for the elderly and young pople dropped out of the school system;

- Civil education and social development;

Physical, health and sexual education and education, etc. (3)

These goals are a tool for social inclusion for less favored young people, including those from ethnic minorities. The social inclusion process ensures that people at risk of poverty and social exclusion are given the opportunities and resources needed to fully 
participate in economic, social and cultural life and enjoy the standard of living and well-being considered normal in society, in That they live. This process guarantees them greater involvement in the decision-making process that affects their lives and greater access to fundamental human rights. (4)

The above objectives of non-formal education are achieved by:

- Interaction, dialogue, mediation communication-based, informal learning approaches:

- Experience, Practice, Experiment -, Nonformal Learning Approaches Based on Activities;

- Partnership, teamwork, networking - socially focused, informal learning approaches;

- Creativity, discovery, responsibility - selfdirected, informal educational approaches. (5)

In the case of work with young people at risk of social exclusion and those from ethnic minorities, alternative forms of education are an opportunity to increase the self-esteem of young people, their ability to live with others, provide moral support and support their socialization. Behind the theory of the need for alternative learning opportunities from the contemporary formal education system, through which social inclusion would be successful, many authors argue.

At the core of education John Dewey puts the experience. It defines the essence of education as organization, reconstruction and transformation of experience. Practice is the starting point, means and purpose of learning, and knowledge is just a function of experience. It is acquired through the understanding of physical activity and the identification of the relationship between the impact of the action and its effects. John Dewey's experience shows that when children have the opportunity to exercise physical activities that carry their natural impulses to play, they go to school with joy and learning is easier. (6)

John Dewey points out that non-formal education is at the core of formal education. He talked about the challenge of maintaining a balance and effectively combining the two forms of training. One of the important issues with which the philosophy of education has to tackle is to find an appropriate balance between informal and formal, incidental and deliberate educational approaches.

According to Ivan Ilich, universal education through education is not feasible. It would be possible if it was done with the help of alternative institutions built on the style of the current schools. It is important for Ilich to release the individuality, i.e. to participate in school and society instead of simple consumption - "Most skills can be acquired and improved through training and discipline, because skill implies mastery of defined and predictable actions." According to Ilich, practical training must be released from the curfew curriculum and the compulsory school attendance. Modern society must rely less on specialized schooling and seek new ways of learning and teaching. According to the author, the real education of man is mostly not the result of training. (7)

In the process of implementation of non-formal education as a specific type of socially meaningful and useful activity, the mechanisms of formation and validation of initial professional and person-oriented competences of young people can be developed. These diverse pedagogical effects contribute to the formation of aesthetic, moral, ethical and legal culture, the formation of ecological thinking; positive social behavior based on respecting the laws of a state and the way in which society operates, increasing the need for self-realization of adaptability to the constantly changing socio-political and economic conditions of the modern world. Modern educational institutions face a drastic need for drastic changes in the theory, method, system, education and education of the younger generation. This need arises from accelerating social development and aims to contribute to the painless social adaptation of young people. (8)

Formal and non-formal education can be seen as aspects of the same process, the basis of which is the complementarity between the two educational models. The effectiveness of nonformal education in terms of social inclusion is reflected in the acquisition of social skills, the acquisition of new knowledge and skills, allowing the successful adaptation of vulnerable groups in a changing environment.

\section{PURPOSE}

The aim of the study is to determine the impact and effectiveness of informal learning approaches on the social inclusion of vulnerable groups with a focus on ethnic minorities. The objective also requires an analysis of the gender outcomes in view of the ethno-cultural specifics of the roma community in the country.

The target group of this study is young people aged between 15 and 29 years.

\section{TASKS}

1. Determine the effectiveness of non-formal education as an approach for social inclusion 
of vulnerable groups with a focus on ethnic minorities.

2. Investigate the effectiveness of non-formal education by gender.

\section{METHODS AND RESULTS}

In the current empirical study, the levels of inclusion in informal educational activities of 259 young people between the ages of 15 and 29, 131 of which from ethnic minorities, were studied. The methods used in the article are analysis of databases, direct observations and information from attendance lists of young people included in the activities of the
International Youth Center for Work with Children and Young People at Risk, Stara Zagora, Bulgaria.

For the purposes of the survey, the activities are divided into four main groups, including non-formal trainings and trainings, sports activities, educational activities - English lessons and leisure activities.

The analysis of the data is based on the level of inclusion of ethnic minority and gender-based youths.

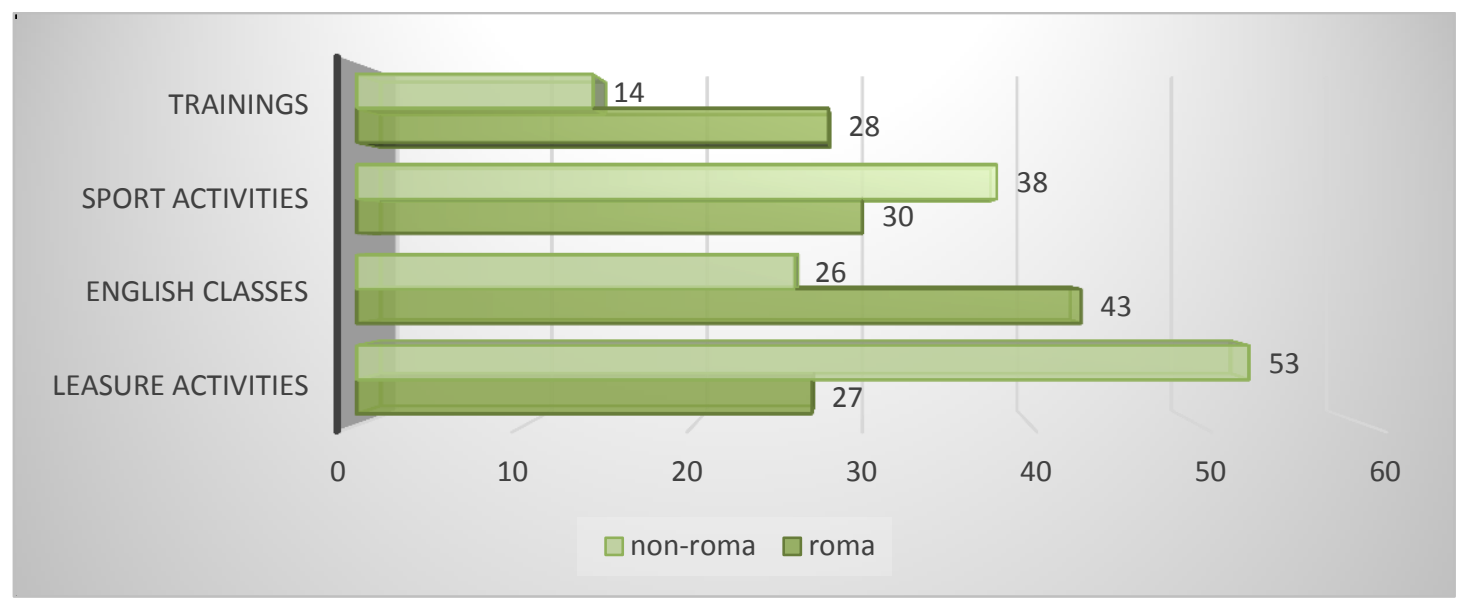

Figure 1. Inclusion rate

By an informal training indicator, low participation rates are observed among ethnic minority representatives - only 14 out of 42 young people aged 15-29 participate actively in the activities. Almost $56 \%$ or 38 out of 68 of the young people in the roma community are involved in sports activities. In terms of educational activities, they are of interest to $37.7 \%$ of men and women of ethnic minorities in the total number of those involved in educational activities. Highest levels of inclusion in the roma community are observed in leisure activities - $66 \%$ or 53 young people out of 80 take active part in informal entertaining activities.

By gender, the results of the survey show that the rate of inclusion in informal activities of women is significantly lower than that of men. Only $28.5 \%$ of them are involved in training modules, and $39.5 \%$ are involved in sporting and recreational activities. (Figure 2)

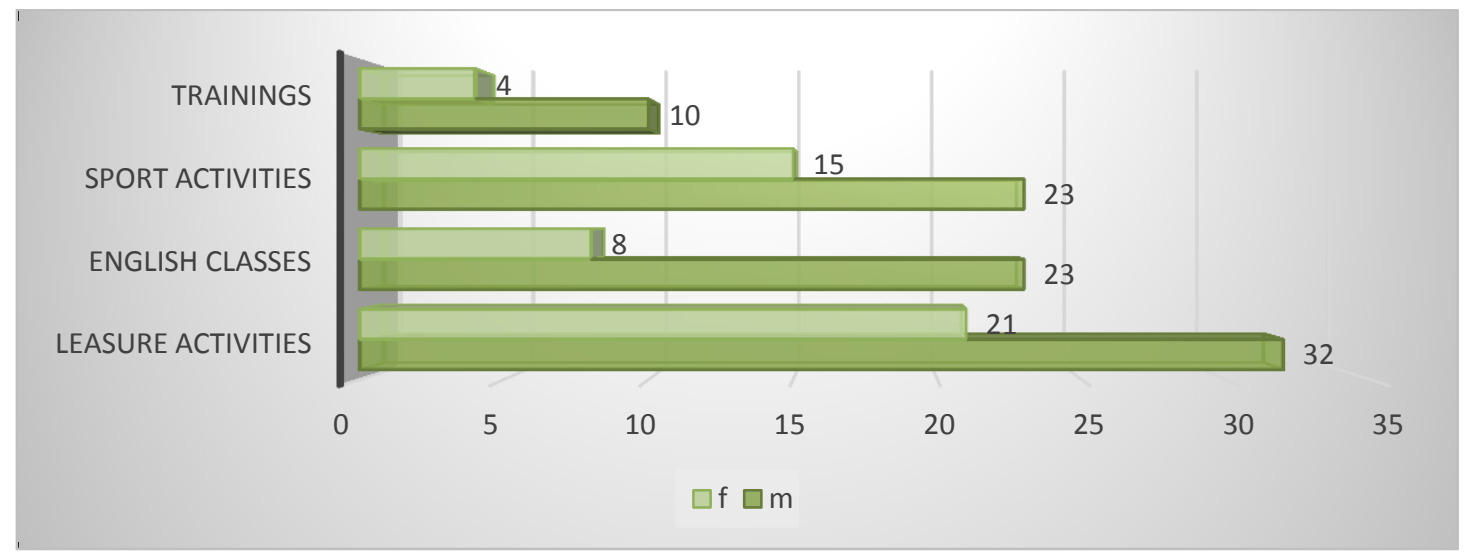

Figure 2. Sexually distribution

By indicator "educational activities", the percentage of inclusion of girls from ethnic minorities is 25.8 .

\section{RESULTS ANALYSIS}

The principle of non-formal education for volunteer participation in activities and 
highlighting the inclusion of participants as an active participant in the learning process is a prerequisite for the interest in activities by representatives of ethnic minorities. The trend that is observed as a result of the study is a higher interest in the entertaining, compared to the educational ones.

Regardless of the type of informal learning activities, the survey data show that extracurricular and extra-curricular forms of education engage part of ethnic minority youth aged 15-29. It should be noted that all the activities under analysis in this article are conducted in mixed groups of young people of roma and non-roma origin. The aim is to provide prerequisites for overcoming the isolation of ethnic minority youths and support for their integration into society.

Free training seminars, English lessons and opportunities to raise their knowledge and skills in a variety of areas are not a priority in the value system of the majority of young roma people. Even in combination with recreational activities, those of a learning nature are not of interest to young people from ethnic minorities.

Data analysis raises the question of the quality and effectiveness of social inclusion through the informal learning approaches of ethnic minority youth, against the background of quantitative inclusion, which will be the subject of further research. Social inclusion as a process that ensures that people at risk of poverty and social exclusion are given equal opportunities and resources is not attained through the non-formal education approaches of ethnic minority groups with a focus on roma.

When analyzing the results by gender indicator, the low levels of inclusion of roma women in non-formal educational activities are impressed. According to the respondents, the main reasons for the low levels of inclusion of women from ethnic minorities in the activities are due to the ethno-cultural specifics of the community.

The patriarchal organization of everyday life in a roma community implies engaging the woman and the girl with household duties and responsibilities to the family. Some of the parents do not allow their daughters to leave the boundaries of roma neighborhoods for security reasons, which is also a prerequisite for the non-inclusion of girls in activities with informal educational profile. By information from female respondents, they are willing to join the class, but the main reason they do not do is the restrictions imposed by their parents. As regards women, the results of the survey indicate that non-formal education as a social inclusion approach is not effective.

Although not the aim of this study, it confirms the thesis of the need to complement the formal and informal learning models. Although the activities analyzed in this article have an informal educational profile, they also use formal approaches to learning and teaching.

\section{CONCLUSION}

As a result of the survey conducted, among the 259 young people aged 15-29, 131 of whom from ethnic minorities, the following main conclusions can be drawn: the study confirms the effect of non-formal educational approaches on the social inclusion of roma youth. It is relatively difficult for women and girls to engage in activities outside the roma neighborhoods, which makes the informal activities approach ineffective for this target group. This trend necessitates the need to bring informal activities to field and work not only with a focus on young people but also with their parents. For this purpose, it is necessary to focus on the development of the knowledge, skills and competences of non-formal education specialists with a focus on ethnic minorities.

The social inequality that the roma community suffers from is a complex problem. It is conditioned by the overlapping of a number of factors including discriminatory practices, social inequality, etc., which to some extent deter social development of the community.

Participation of young people from ethnic minorities in informal activities is a step towards successful educational integration and social inclusion of the roma community. Nonformal education is a necessary element in the process of modernization of Bulgarian and European education. The self-employed use of non-formal education does not always give a chance for the further development of young people, indicating the need to integrate nonformal learning approaches into formal education.

\section{REFERENCES}

1. EU - CoE youth partnership policy sheet social inclusion, Siyka Kovacheva http://pjp-eu.coe.int/en/web/youthpartnership/social-inclusion

2. T-kit on social inclusion, T. Croft, V. Crolla, Council of Europe and European Commission, 2003, p.37

3. Non-formal education. Philosophies. Theories. Practices, Silvia Nikolaeva, Sofia 2015, $40 \mathrm{p}$ 
4. Joint report on social inclusion, European Commission, 2004, page 10.

5. Council of Europe Symposium on NonFormal Education: Report, 2001, page 6

6. The Project Gutenberg EBook of Democracy and Education, J. Dewey, 2015 /http://www.gutenberg.org/files/852/852h/852-h.htm\#link2HCH0001/
7. Exemption from schools. Proportionality and the Modern World, Ivan Illich, p.17, 25

8. Integration of formal and non-formal education of children and adults on the example of a small-town children's and youth sports school, VE Malgin, Mokrousov SV, Young scientist. 2014. S. 578-580. 